\title{
Photosynthetic Activity of Cup Plant Depending on the Method of Seeding
}

\section{Marina P. Chupina and Aleksandr F. Stepanov}

Omsk State Agrarian University, Institutskaya ploshchad, 1, Omsk, Russia

ORCID:

Marina P. Chupina: http://orcid.org/0000-0001-6672-5125

\section{Abstract}

Biological farming throughout the world is becoming a necessity for the production of safe products, and the preservation of fertility and biodiversity. In this direction, there is a significant interest of the scientific community in the perennial culture - cup plant. The cup plant has a wide range of uses in economic activities and due to its high resistance to diseases and pests, the long-term use of its plantations without replanting, and the accumulation of a significant mass of organic matter in the soil, it can be used to expand the species diversity of perennial grasses in the biological farming system. The aim of the study was to examine the influence of the seeding method and seeding rate on

Corresponding Author: Marina P. Chupina mp.chupina@omgau.org

Published: 5 April 2021

Publishing services provided by Knowledge E

(c) Marina P. Chupina and Aleksandr F. Stepanov. This article is distributed under the terms of the Creative Commons Attribution License, which permits unrestricted use and redistribution provided that the original author and source are credited.

Selection and Peer-review under the responsibility of the DonAgro Conference Committee.

\section{G OPEN ACCESS} photosynthetic activity and dry matter productivity of the cup plant in the forest-steppe conditions of Western Siberia. It was found that with an ordinary method of sowing at a seeding rate of 4 million pcs/ha, the grass stand in the first cut had the highest rates of photosynthetic activity on average over the years of research: the leaf area was 14.8 $\mathrm{m}^{2} / \mathrm{m}^{2}$, the photosynthetic potential was 4.0 million $\mathrm{m} 2$ day/ha and the net productivity of photosynthesis was $2.0 \mathrm{~g} / \mathrm{m}^{2}$. day. In the second cut, the figures were $8.4 \mathrm{~m}^{2} / \mathrm{m}^{2}, 1.9$ million $\mathrm{m}^{2}$ day/ha and $2.8 \mathrm{~g} / \mathrm{m}^{2}$. day, respectively. The optimal density of herbage and active photosynthetic activity in the cup plant using this method of sowing contributed to a significant yield of dry matter of 12.6 t/ha with a high level of PAR absorption of $2.9 \%$.

Keywords: cup plant, yield, photosynthesis, sowing method

\section{Introduction}

Agriculture in the modern world should develop towards the biologization and greening of all its processes, which is due to the right of every person to biologically complete products and a safe living environment [1]. On the basis of this approach to the development of the agricultural sector, agriculture should be based on the widespread use of technologies that save resources and energy, on reducing the level of use of chemicals, on maintaining and increasing soil fertility by activating the cycle of substances (organic fertilizers, symbiotic nitrogen fixation, siderats) and on the expansion of the species and varietal diversity of cultivated ecologically sustainable crops $[2,3]$. 
In the farming system aimed at biologization, the role of perennial grasses, their importance and proportion in crop rotations will increase, which means that the requirements for cultivated species and varieties will increase [4]. Therefore, they should not only have high ecological plasticity and productivity (including in a changing climate), but also be able to play a soil protective, phytosanitary and phytomeliorative role [2].

Currently, in the world, and in particular in the Russian Federation, there is a significant scientific and industrial interest in the perennial culture of cup plant (Silphia perfoliatum L.). This is largely due to the wide range of its uses. In Europe and North America, cup plant, or silphia, is mainly used as a bioenergy crop for biogas production and is considered a good alternative to corn [5-7]. In Russia, this crop is cultivated mainly as a fodder plant for early and late green fodder and for harvesting silage [8]. Silphia is recognized all over the world as a valuable plant for the production of high-quality honey by bees. The advantage of using this crop as a melliferous crop is its long flowering from July to September, when the food supply for bees is no longer distinguished by a great variety of species $[8,9]$. Long-term studies of silphia have shown that various parts of this plant are rich in biologically active substances (essential oils, phenolic acids, saponins, flavonoids, etc.), which indicates the great potential of using this culture as a raw material for pharmaceutical industry [5]. Triterpene glycosides (sylphiosides) extracted from silphia leaves are recommended for use as growth regulators in cereals and horticultural crops [10].

Silphia forms a significant volume (100 t/ha) of green mass during the growing season, fights weeds perfectly, has a high degree of resistance to diseases and pests, is distinguished by longevity (10-20 years) of industrial use of plantations with possible accumulation in the soil up to $10 \mathrm{t} / \mathrm{ha}$ of organic matter $[5,8]$. Due to the powerfully developed root system, which penetrates into the deep layers of the soil, silphia, when grown for a long time on drained soils, leads to a decrease in the level of groundwater and an acceleration of drainage at the site [11]. Thus, according to the above features, Silphia has a high ecological efficiency of cultivation and can expand the species diversity of perennial crops in fodder production and in other areas of economic activity in the harsh climatic conditions of Western Siberia. The productivity of agrophytocenosis is largely determined by its photosynthetic activity, which in turn depends on the size of the leaf surface of plants and the ecological conditions of the external environment. The process of photosynthesis of plants can to some extent be controlled, creating optimal conditions for their growth and development through the elements of cultivation technology, including through the formation of optimal plant density. When assessing the effect of agricultural technology elements on the productivity of agrophytocenosis, 
it is necessary to use the following main parameters characterizing the process of photosynthesis: leaf area, net productivity of photosynthesis (NPP), photosynthetic potential (PP), and efficiency of photosynthesis [12].

The aim of the study is to reveal the influence of the sowing method and the seeding rate on the photosynthetic activity and productivity of the sup plant in the conditions of the forest-steppe of Western Siberia

\section{Methods and Equipment}

The study was carried out on the experimental field of the Omsk Agrarian University, the city of Omsk, located in the forest-steppe zone of Western Siberia $\left(54.94^{\circ}\right.$ north latitude and $73.36^{\circ}$ east longitude, $90 \mathrm{~m}$ above sea level). The zone is characterized by a continental climate with an average annual rainfall of $400 \mathrm{~mm}$ and an average annual air temperature of $1.7^{\circ} \mathrm{C}$. The soil type is meadow chernozem with neutral acidity $(\mathrm{pH}$ 6.7-7.4), a humus content of $3.4 \%$ and following content of nutrients: $12 \mathrm{~m}$ of

$\mathrm{N}-\mathrm{NO}_{3}, 284 \mathrm{mg}$ of $\mathrm{P}_{2} \mathrm{O}_{5}$ and $225 \mathrm{mg}$ of $\mathrm{K}_{2} \mathrm{O}$ per $1 \mathrm{~kg}$ of soil. During the years of research, the meteorological conditions for the warmth and moisture supply during the growing season of the silphia were favorable for its growth and the formation of the green mass yield.

The experiment was carried out on black fallow in 4-fold repetition with the accounting area of the plots of $25 \mathrm{~m}^{2}$. Silphia sowing was carried out in early May in three ways: ordinary, with a row spacing of $15 \mathrm{~cm}$; wide-row with the spacing of 45,70 and $90 \mathrm{~cm}$; and square-nested with the dimensions of $70 \times 70 \mathrm{~cm}$. All agrotechnical activities in the experiment were carried out according to the general recommendations for this zone. In the first year of herbage life, the green mass of silphia was mown once in the phase of a rosette of leaves. In subsequent years of using the grass stand, the first cut was carried out in the phase of the beginning of flowering, the second was in the phase of stalking.

In the first three years of the crop life during its growing season, in the first and second cut, the leaf area was determined by the method of cutting, the yield of green mass was defined by the continuous method and the output of dry matter was determined at the Center for Collective Use "Agrarian and Technological Research" [13]. The photosynthetic potential, net productivity of photosynthesis, and the efficiency of photosynthesis (PAR efficiency) of silphia crops were determined by the calculation method [14]. The experimental data were subjected to dispersion and correlation analysis [15]. 


\section{Results}

According to the data obtained, in the first year of herbage life during the growing season of 110 days, with the ordinary method of sowing, silphia formed the largest leaf area of $6.9-7.4 \mathrm{~m}^{2} / \mathrm{m}^{2}$ depending on the seeding rate, while with square-nesting (70 $\times 70$ $\mathrm{cm}$ ) sowing this value was minimal and did not exceed $4.8-5.3 \mathrm{~m}^{2} / \mathrm{m}^{2}$ (Figure 1). In the second year of life in the first cut, the area of leaves on silphia crops with all studied sowing methods increased 2.5-3.2 times compared to the first year. Such a significant increase in the area of the assimilation apparatus is due to the peculiarity of the culture in the first year of life to form only a rosette of 6-18 leaves, depending on the method of sowing, and from the second and subsequent years, to form a full-fledged herbage from the shoots. At the same time, in this year, silphia had the largest leaf area during row sowing both in the first $\left(17.9-18.3 \mathrm{~m}^{2} / \mathrm{m}^{2}\right)$ and in the second cut $\left(7.8-8.5 \mathrm{~m}^{2} / \mathrm{m}^{2}\right)$ due to the increased herbage density.

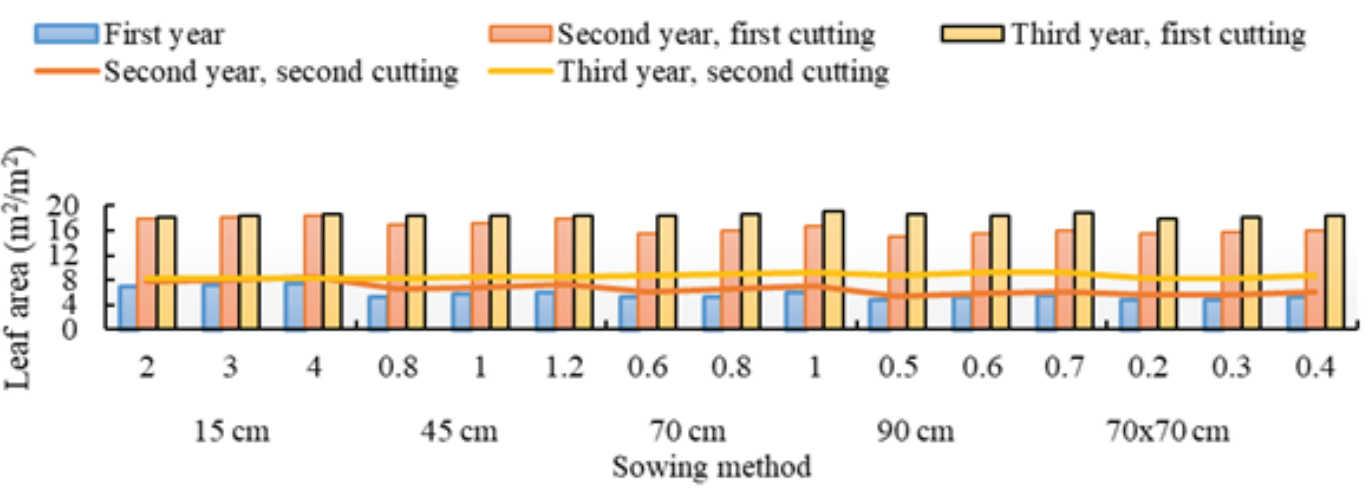

Figure 1: Area of the leaves of cup plant depending on the method of sowing and sowing rate, $\mathrm{m}^{2} / \mathrm{m}^{2}$

In the third year of life, in the first cut, a tendency to leveling the area of leaves of silphia was observed depending on the sowing method and the seeding rate, which varied from 18.2 to $19.1 \mathrm{~m}^{2} / \mathrm{m}^{2}$, while in the second cut, the largest photosynthetic apparatus $\left(9.1-9.3 \mathrm{~m}^{2} / \mathrm{m}^{2}\right)$ was formed on crops with a row spacing of 70 and $90 \mathrm{~cm}$ at a seeding rate of 0.6-1.0 million pcs./ha. Moreover, the leaf area in this year of use with these sowing methods and seeding rates increased by $14-15 \%$ in the first cut and by $30-58 \%$ in the second cut compared to the previous year. The area of the leaf surface of the silphia in the second mowing during the years of research was 2-3 times less than in the first mowing, which is associated with a significant decrease in the rate of development of grass leaves during the aftergrowth formation.

The photosynthetic work of agrophytocenosis by the size and duration of the work of the assimilatory apparatus is assessed by the photosynthetic potential. In the first 
year of the life of the silphia grass stand, the highest photosynthetic potential during the growing season was formed with the row sowing method (1.8-2.1 million $\mathrm{m}^{2}$ day/ha), while as the row-spacing increased, this indicator decreased 1.4-3.5 times (Figure 2).

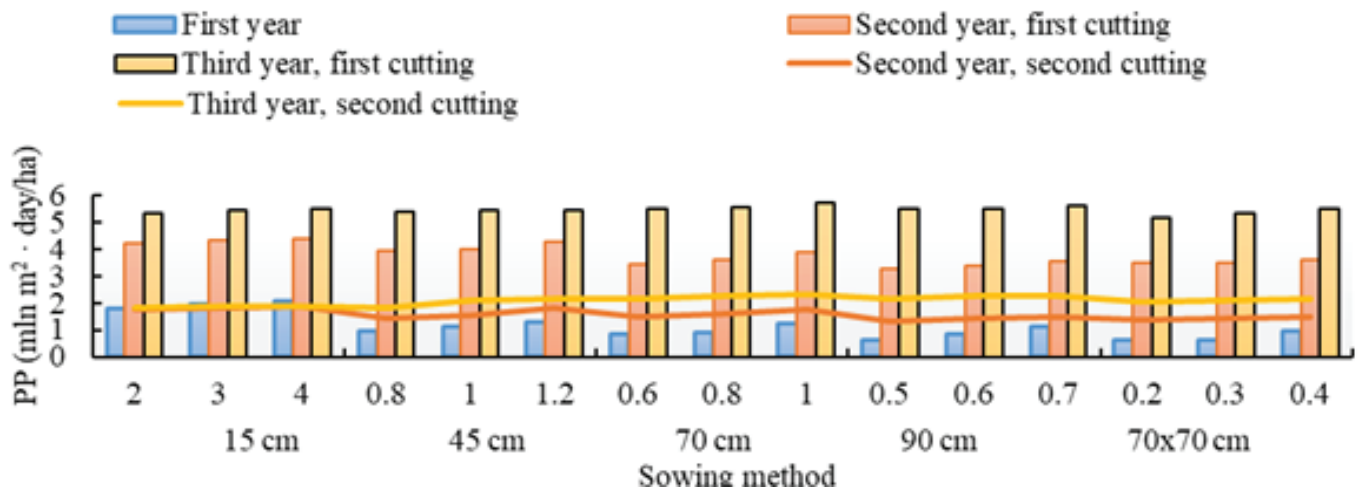

Figure 2: Photosynthetic potential (PP) of cup plant depending on the sowing method and seeding rate, million $\mathrm{m}^{2} \cdot$ day/ha

In the second year of life, the advantage in the value of the photosynthetic potential both in the first (4.2-4.4 million $\mathrm{m}^{2}$ day/ha) and in the second (1.8-1.9 million $\mathrm{m}^{2}$ day/ha) mowing was in silphia crops with a width row spacing $15 \mathrm{~cm}$. Increasing the row spacing up to $90 \mathrm{~cm}$ and the square-nest sowing method reduced this indicator by $20-36 \%$. In the third year of life in the first cut, insignificant changes in the photosynthetic potential were observed depending on the sowing method (5.2-5.7 million $\mathrm{m}^{2}$ day/ha), which is due to the equalization of the density of the grass stand with wide-row and square-nest sowing methods due to good shoot-forming ability of silphia. However, in the second cut with wide-row crops $(70$ and $90 \mathrm{~cm}$ ), due to more optimal conditions for growth and development, the silphia formed a more powerful assimilation apparatus, which determined the high photosynthetic potential of its herbage (2.2-2.3 million $\mathrm{m}^{2}$ day/ha).

The quality of the assimilation apparatus was assessed by the indicator net productivity of photosynthesis, the maximum value of which in the first year of life was noted on the variants with the smallest leaf area and photosynthetic potential, namely, on square-nested and wide-row sowing methods at minimum seeding rates $\left(1.1-1.3 \mathrm{~g} / \mathrm{m}^{2}\right.$ day) (Figure 3).

In subsequent years, an annual increase in the net productivity of photosynthesis of silphia crops was observed, which was manifested to a greater extent with the row sowing method, where, due to the compaction of the herbage, the main part of the leaves was located in the upper tier with less shading. Thus, the net productivity of photosynthesis in the first mowing in the second year increased by 1.2-2.9 times, and by the third, by 1.2-1.5 times compared to the first year. In the second year of life, the smallest NPP was on the square-nesting $70 \times 70 \mathrm{~cm}$ method of sowing in the first cut 
(1.61-1.63) while in the second cur it was $1.36-1.64 \mathrm{~g} / \mathrm{m}^{2}$. day, which is $11-38 \%$ inferior to other methods of sowing. In the third year of life, the tendency for a decrease in the net productivity of photosynthesis of sowing with an increase in the row spacing also persisted in the first cut by $7-36 \%$, in the second it increased by $21-30 \%$.

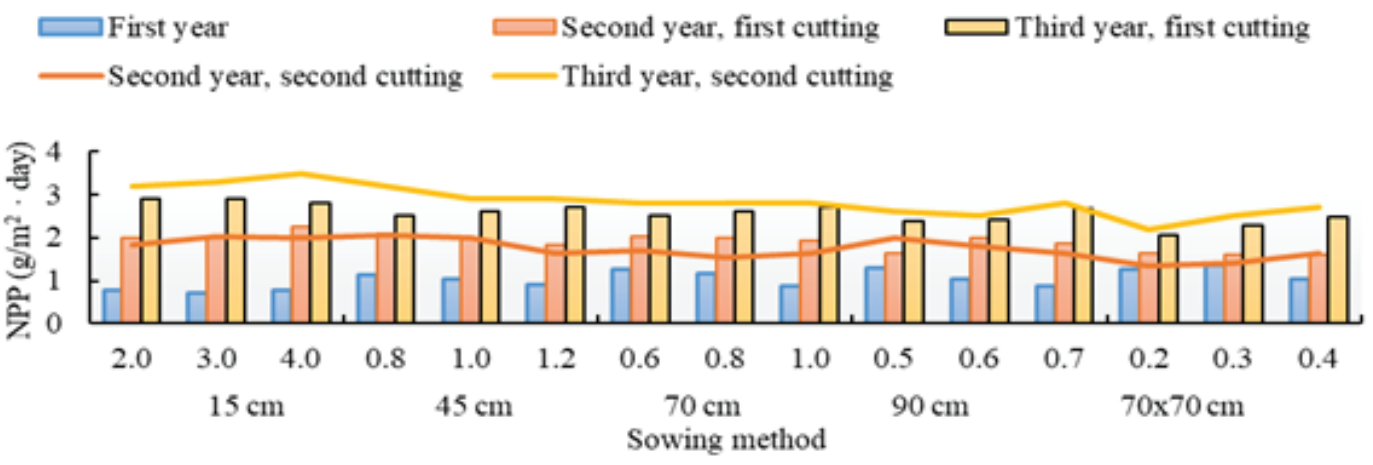

Figure 3: Net productivity of photosynthesis (NPP) of cup plant, depending on the sowing method and the seeding rate, $\mathrm{g} / \mathrm{m}^{2}$. ha

In the first year of life, the yield of dry matter from silphia crops was not high and varied from 0.8-1.0 $\mathrm{t} / \mathrm{ha}$ with a square-nest sowing method to 1.4-1.6 $\mathrm{t} / \mathrm{ha}$ with an ordinary one (Figure 4). An increase in the productivity of the silphia grass stand was observed in the second and third years of life. For example, in the second year of life, the yield of dry matter per unit area increased 5-10 times, in the third year it increased 14-22 times compared to the first year of life. The best options were with row and wide-row sowing methods at increased seeding rates, where the dry matter productivity in the second year of life was 10.2-13.7 t/ha, and in the third year it was 21.1-22.4 t/ha.

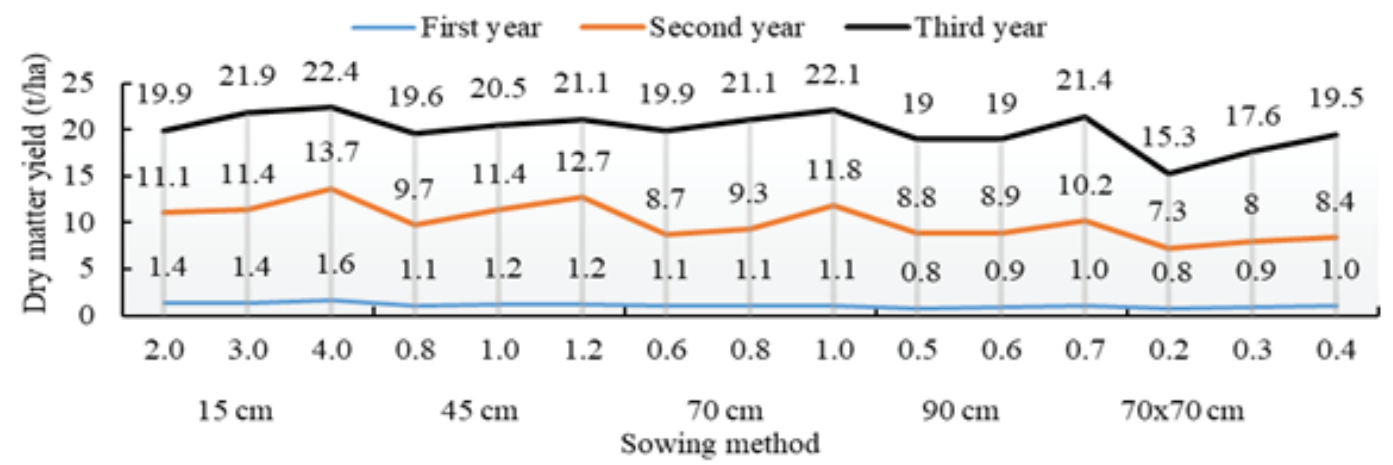

Figure 4: Productivity of cup plant, depending on the sowing method and seeding rate, $t /$ ha

The efficiency of the assimilation apparatus of the silphia crops, depending on the sowing method and the seeding rate, was assessed by the efficiency of photosynthesis, which for grass stand with an average level of PAR assimilation should be within 1.5$3.0 \%$, and $3-5 \%$ at its high level [14]. Already in the second year of the life of the silphia 
stand, with row and wide-row sowing methods $(45$ and $70 \mathrm{~cm})$ at seeding rates of 1.0-4.0 million pcs/ha, the average value of PAR assimilation reached 1.5-1.8\% (Figure 5).

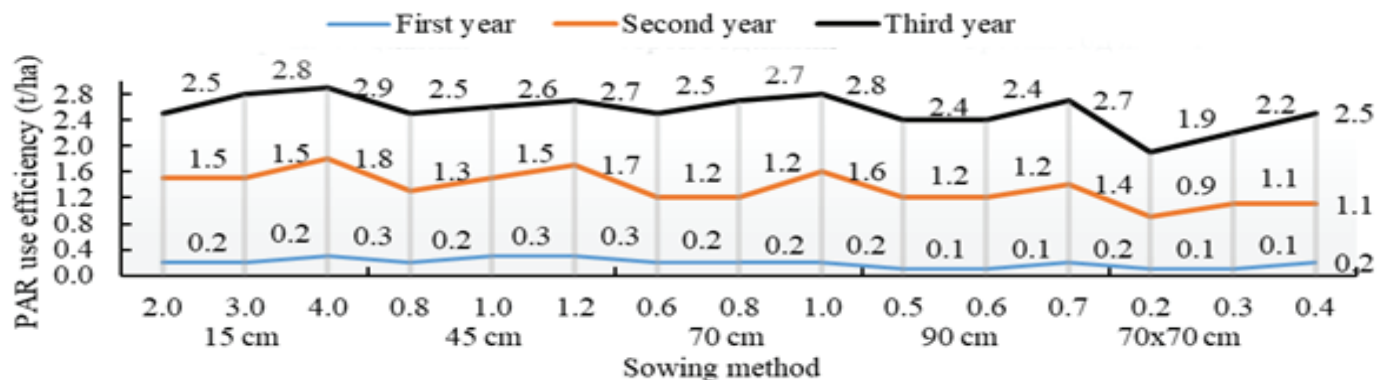

Figure 5: PAR use efficiency of silphia crops depending on the sowing method, seeding rate and year of life, \%

By the third year of life, this indicator increased by another 1.7-2.3 times in all variants of the experiment, and the most effective use of PAR was noted on crops with the highest seeding rate.

\section{Discussion}

In the course of assessing the degree of the influence of photosynthetic parameters on the yield of dry matter of silphia, depending on the method of sowing and the seeding rate, a correlation analysis was used. A strong correlation was revealed between the productivity of the herbage and the leaf area $(r=0.93 \pm 0.1)$, the photosynthetic potential $(r=0.9 \pm 0.11)$, and the net productivity of photosynthesis $(r=0.82 \pm 0.15)$.

\section{Conclusion}

The study of the photosynthetic activity of cup plant with various sowing methods in the forest-steppe conditions of Western Siberia showed that on a row sowing of silphia with a seeding rate of 4 million units/ha, an optimal density of herbage was formed, which contributed to the formation of a powerful assimilation apparatus with a high photosynthetic potential. These indicators on average over the years of research were, respectively, $14.8 \mathrm{~m}^{2} / \mathrm{m}^{2}$ and 4.0 million $\mathrm{m}^{2}$ day/ha in the first cut and $8.4 \mathrm{~m}^{2} / \mathrm{m}^{2}$ and 1.9 million $\mathrm{m}^{2}$. day/ha in the second cut. This sowing method was also distinguished by the more productive work of the assimilation apparatus of the grass stand, which is confirmed by the high average values of the net productivity of crops on this variant of the experiment in the first $\left(2.0 \mathrm{~g} / \mathrm{m}^{2}\right.$ day $)$ and in the second $\left(2.8 \mathrm{~g} / \mathrm{m}^{2} \cdot\right.$ day $)$ cutting. Significant indices of photosynthetic activity of silphia crops during drill sowing with 
a seeding rate of 4 million pcs/ha determined the high yield of dry matter, which on average over the years of research and for two cuts was $12.6 \mathrm{t} / \mathrm{ha}$. The photosynthetic activity of silphia crops noticeably increased with the age of the grass stand, which was especially evident in an increase in the efficiency of PAR by 10-14 times by the third year of life of the grass stand as compared to the first one, and with a row sowing and a seeding rate of 4 million pcs./ha, a high level of PAR assimilation was achieved (2.9\%).

\section{Funding}

\section{Acknowledgement}

The research was carried out on the equipment of the center for collective use of Omsk state agrarian University "Agrarian and technological research".

\section{Conflict of Interest}

The authors have no conflict of interest to declare.

\section{References}

[1] Das, S., Chatterjee, A. and Pal, T. (2020). Organic Farming in India: A Vision towards a Healthy Nation. Food Quality and Safety, vol. 20, pp. 1-8.

[2] Zhuchenko, A. A. (2009). Biologization and Greening of Intensification Processes in Agriculture. Bulletin of the Oryol State Agrarian University, vol. 3, pp. 8-12.

[3] Growder, D. and Reganold, J. (2015). Financial Competitiveness of Organic Agriculture on a Global Scale. Proceedings of the National Academy of Sciences, vol. 112 , issue 24 , pp. 7611-16.

[4] Ruf, T., et al. (2018). Soil Quality Indicator Response to Land-Use Change from Annual to Perennial Bioenergy Cropping Systems in Germany. GCB Bioenergy, vol. 10, issue 2, p. 12513.

[5] Cumplido-Marin, L., et al. (2020). Two Novel Energy Crops: Sida Hermaphrodita (L.) Rusby and Silphium Perfoliatum L. - State of Knowledge. Agronomy, vol. 10, issue 7, p. 928.

[6] Schorpp, Q., et al. (2016). Agro-Ecological Potential of the Cup Plant (Silphium Perfoliatum L. from a Biodiversity Perspective. Journal für Kulturpflanzen, vol. 68, pp. 412-22. 
[7] Siwek, M., et al. (2019). Chemical Composition Biogas Formation Potential of Sida Hermaphrodita and Silphium Perfoliatum. Applied Sciences, vol. 9 (19), p. 4016.

[8] Stepanov, A. F. and Chupina, M. P. (2018). Cup Plant: Biology, Agricultural Technology, Use. Omsk: Publishing House of Omsk SAU.

[9] Mueller, A., et al. (2019). Water Availability Affects Nectar Sugar Production and Insect Visitation of the Cup Plant Silphium perfoliatum L. (Asteraceae). Journal of Agronomy and Crop Science, vol. 0, pp. 1-9.

[10] Davidyants, E. S. (2019). Effect of the Purified Sum of Triterpene Glycosides and the Enriched Extract from the Leaves of Silphium Perfoliatum L. on the Growth and Activity of Nitrate Reductase in Winter Wheat Plants. Plant Chemistry, vol. 4, pp. 441-48.

[11] Zinkovskaya, T. S., Kovalev, N. G. and Zinkovsky, V. N. (2017). Water Consumption and Meliorative Functions of Silphia (Silphium Perfoliatum L.) on Drained Soddy-Podzolic Soil. Agrophysics, vol. 2, pp. 47-53.

[12] Popolzukhina, N. A., et al. (2019). Photosynthetic and Symbiotic Efficiency in Shaping the Yield of Pea Seed in the Agro-Ecological Conditions of the Southern ForestSteppe of Western Siberia. IOP Conf. Series: Earth and Environmental Science, vol. 315, p. 62028.

[13] Novoselov Yu.K. et al. (1997). Methodical Instructions for Conducting Field Experiments with Forage Crops. Moscow: Russian Agricultural Academy.

[14] Nichiporovich, A. A. (1969). Methodical Instructions for Accounting and Control of the Most Important Indicators of the Processes of Photosynthetic Activity of Plants in Crops. Moscow: USSR Academy of Sciences Publishing House.

[15] Dospekhov, B. A. (1973). Field Experiment Technique. Moscow: Kolos. 